University of Nebraska - Lincoln

DigitalCommons@University of Nebraska - Lincoln

\title{
Nonoffending Parent Expectations of Sexually Abused Children: Predictive Factors and Influence on Children's Recovery
}

Haig Kouyoumdjian

University of Nebraska-Lincoln

Andrea R. Perry

University of Nebraska-Lincoln, andreaperry1@yahoo.com

David J. Hansen

University of Nebraska-Lincoln, dhansen1@unl.edu

Follow this and additional works at: https://digitalcommons.unl.edu/psychfacpub

Part of the Psychiatry and Psychology Commons

Kouyoumdjian, Haig; Perry, Andrea R.; and Hansen, David J., "Nonoffending Parent Expectations of Sexually Abused Children: Predictive Factors and Influence on Children's Recovery" (2009). Faculty Publications, Department of Psychology. 546.

https://digitalcommons.unl.edu/psychfacpub/546

This Article is brought to you for free and open access by the Psychology, Department of at DigitalCommons@University of Nebraska - Lincoln. It has been accepted for inclusion in Faculty Publications, Department of Psychology by an authorized administrator of DigitalCommons@University of Nebraska - Lincoln. 
Published in Journal of Child Sexual Abuse, 18 (2009), pp. 40-60; doi: 10.1080/10538710802584627

Copyright () Taylor \& Francis Group, LLC. Used by permission.

Submitted November 10, 2005; revised May 5, 2006, and September 7, 2007;

accepted November 29, 2007.

This paper is based on Haig Kouyoumdjian's doctoral dissertation. An earlier version of this paper was presented at the 38th Association for Advancement of Behavior Therapy Conference in November 2004. The authors extend a special thanks to the staff and therapists involved in Project SAFE (Sexual Abuse Family

Education) at University of Nebraska-Lincoln for their assistance with this project.

\title{
Nonoffending Parent Expectations of Sexually Abused Children: Predictive Factors and Influence on Children's Recovery
}

\author{
Haig Kouyoumdjian, Andrea R. Perry, and David J. Hansen \\ University of Nebraska-Lincoln, Lincoln, Nebraska, USA \\ Corresponding author - Andrea R. Perry, email andreaperry1@yahoo.com
}

\begin{abstract}
This study examined the influence of parental expectations on the functioning of sexually abused children. Participants included 67 sexually abused youth and 63 of their nonoffending primary caregivers. Parental expectations about how sexual abuse will impact children were predictive of parents' ratings of children's behavior at pretreatment, while parental expectations of children's overall future functioning were not predictive of parents' ratings of children's behavior. Parental expectations about how sexual abuse will impact their children and about their children's overall future functioning were not predictive of parents' ratings of children's behavior at posttreatment. Results highlight the influential role the sexual abuse label has in shaping parental expectations about children's functioning. Recommendations for research and intervention are discussed.
\end{abstract}

Keywords: sexual abuse, labeling, expectancies, expectations, recovery

Although a portion of child sexual abuse (CSA) victims may be asymptomatic in the aftermath of abuse (see Kendall-Tackett, Williams, \& Finkelhor, 1993), 
CSA consistently has been linked to myriad adverse short- and long-term consequences, including difficulties in mental health, behavioral functioning, and interpersonal relationships (see Beitchman et al., 1992; DiLillo, 2001; Paolucci, Genuis, \& Violato, 2001; Polusny \& Follette, 1995; Putnam, 2003). To shed light on the significant variability in CSA sequelae, researchers have investigated the influence of several mediating and moderating variables on symptom development. Two family factors that have amassed substantial empirical attention are (a) parental reactions to disclosure of CSA and (b) parental support in the aftermath of CSA. For both factors, research has shown that the recovery of sexually abused children is, in part, associated with how the parent reacts and responds to the child's disclosure of CSA. In a treatment study, Cohen and Mannarino $(1996,1998)$ documented significant linkages between parents' negative emotional reactions (e.g., fear, embarrassment) to children's CSA disclosure and children's posttreatment internalizing, externalizing, and behavioral symptoms, a finding that was somewhat maintained when the families were reassessed 6 and 12 months later. Similarly, the presence of parental support post CSA disclosure has been found to be associated with positive outcomes in sexually abused children (e.g., Cohen \& Mannarino, 1998; Spaccarelli \& Kim, 1995), whereas the absence of parental support has been linked to increased internalizing and externalizing difficulties (e.g., Adams-Tucker, 1982). These effects not only appear in child victims but also in adolescents and adults reporting retrospectively about their CSA histories (e.g., Beitchman et al., 1992; Guelzow, Cornett, \& Dougherty, 2002; Morrison \& Clavenna-Valleroy, 1998).

In light of these significant linkages, it is likely that research examining additional family variables will help to clarify the diverse recovery processes of sexually abused children. An underresearched yet potentially important variable is the way in which parental expectations (e.g., beliefs of how a child will respond to CSA) may impact recovery (Kouyoumdjian, Perry, \& Hansen, 2005). Two interrelated research literatures provide a solid framework for investigating the role of parental expectations on children's recovery from CSA. This research includes studies that demonstrate the influential role of adults' expectations on the behavioral and emotional functioning of several groups of children (e.g., gifted children) as well as studies that reveal the ways in which

a child being labeled as "abused" influences the perceptions and behaviors of teachers, mental health professionals, and parents (see review by Kouyoumdjian et al., 2005),

\section{The Impact of Adult Expectations on Sexually Abused Children}

Researchers have discussed how labeling an individual can, in some instances, encourage the "labeled" individual to engage in behaviors that re- 
flect stereotypical (or expected) aspects of the label, a phenomenon referred to as the self-fulfilling prophecy (e.g., Briggs, Hubbs-Tait, Culp, \& Blankemeyer, 1995; Holguin \& Hansen, 2003; Jussim, Eccles, \& Madon, 1996; Madon, Jussim, \& Eccles, 1997). Research has consistently confirmed the powerful (and often negative) influences of adults' expectations on children who are gifted, disadvantaged (e.g., learning disabled, brain injured), and from varying family structures (e.g., Clark \& Artiles, 2000; Freund, Bradley, \& Caldwell, 1979; Guttmann \& Broudo, 1988/1989; Touliatos \& Lindholm, 1974). In light of the powerful impact of adults' expectations on the functioning of various groups of children, researchers more recently have begun to explore adults' perceptions of and interactions with sexually abused children. Because CSA is linked to a range of short- and long-term sequelae, the CSA label may encourage adults to make assumptions about the abused child's functioning and consequently to have more negative expectations for the child (Holguin \& Hansen, 2003; Kouyoumdjian et al., 2005). In addition to the effects of the abuse label, research using vignettes to ascertain adults' perceptions of CSA consistently indicates biases based on characteristics of the abuse scenario. For example, scenarios that portray an adult female perpetrating against a younger male are frequently perceived by college students as being less detrimental than those comprised of an adult male and a younger female (e.g., Smith, Fromuth, \& Morris, 1997), and heterosexual dyads are seen as less damaging than either of the same-gender scenarios (e.g., Dollar, Perry, Fromuth, \& Holt, 2004; Maynard \& Wiederman, 1997). As a whole, these results reveal that adults do not perceive all abuse equally, which may translate into ways in which adults interact with sexually abused children.

Teachers appear to be influenced by the "sexual abuse" label both in terms of how they rate the child's expected outcomes and how they perceive the child's role in the abuse incident (Holguin \& Hansen, 2003; Kouyoumdjian et al., 2005). In a study by Bromfield, Bromfield, and Weiss (1988), teachers rated sexually abused children as being somewhat more adept at solving puzzles and yet as more likely to exhibit future problems on puzzle tasks. Research also has demonstrated that the attitudes of school personnel are shaped by certain characteristics of the abuse. For instance, in a two-part study, school personnel rated vignettes describing a sexual encounter that occurred between a father and a "passive," "resistant," or "encouraging" daughter while the mother was away shopping. Although some differences emerged based on rater characteristics (e.g., rater age), professionals in this study rated the "encouraging" child as more blameworthy (Ford, Schindler, \& Medway, 2001). Additionally, a study by Hicks and Tite (1998) revealed that school personnel and police officers, in contrast to social workers, were less likely to find a CSA victim as being credible.

Research consistently indicates that professionals who work with sexually abused children-including child protective workers, social workers, counselors/therapists, and police-are also vulnerable to the CSA label and the ef- 
fects of abuse characteristics. For example, social workers and police officers applied more severe legal sanctions to vignettes involving male-perpetrated abuse compared to female-perpetrated abuse (Hetherton \& Beardsall, 1998). Other research has indicated that mental health professionals perceive sexually abused children to have greater psychological and behavioral difficulties. In a study by Holm, Holguin, and Hansen (2002), various groups of mental health professionals overwhelmingly rated children with a CSA label as being more negatively impacted in a wide range of contexts, including social-emotional, behavioral, and academic functioning. Taken together, these findings indicate that professionals, too, have difficulty escaping the effects of labeling and may have lowered expectations regarding the short- and long-term outcomes of sexually abused children.

Although studies have yet to explicitly examine the role of parents' expectations on the behavioral and emotional functioning of children, research to date has shown that adults view sexually abused children as having a heightened amount of short- and long-term difficulties. In a particularly revealing series of studies, undergraduate students reported that sexually abused children would experience the greatest number of internalizing and (in some cases) externalizing difficulties when compared to children from "normal" families (Briggs, Hubbs-Tait, Culp, \& Morse, 1994; Saathoff-Wells, Culp, \& Yancey, 2005) and children whose mother has terminal cancer (Briggs et al., 1994, 1995; SaathoffWells et al., 2005).

\section{Present Study}

Adults' expectations of children's functioning are shaped by various characteristics of the child, such as giftedness, disability status, family background, and sexual abuse history. As discussed by Kouyoumdjian et al. (2005), it is possible that adults' negative expectations of sexually abused children may directly "influence the development of symptomatology in children in ways that supersede any deleterious effects caused by the actual abuse" (p. 486). More specifically, adults' negative expectations may increase the likelihood that they will interact in negative ways with sexually abused children (e.g., portraying lowered expectations), which may maintain or exacerbate CSA sequelae (see Briggs et al. [1995] and reviews by Holguin \& Hansen [2003] and Kouyoumdjian et al. [2005]).

Although adults' expectations of sexually abused children are important, particularly in determining whether such expectancies maintain CSA symptomatology, few studies have explored this variable. Thus, the current study sought to examine how parental expectations of sexually abused children impact children's recovery from the abuse. The current study had two primary 
goals: (a) to examine the relationship of parental expectations (i.e., parental expectations about their children's future functioning and future symptomatology based on the child's history of sexual abuse) with the children's emotional and behavioral functioning prior to treatment, and (b) to examine the relationship of pretreatment parent expectations with their children's emotional and behavioral functioning posttreatment.

\section{Method}

\section{Participants}

Participants included 67 sexually abused children (16 boys and 51 girls) and 63 nonoffending parents (or caregivers) who participated in Project SAFE (Sexual Abuse Family Education), a curriculum-led cognitive-behavioral group treatment program for sexually abused children and their nonoffending parents. Participants included some children who entered treatment without a nonoffending parent (e.g., children in foster care) and some parents who entered treatment without their children (e.g., child too young to participate). Although only one child per family was utilized in this study, four nonoffending parents participated with two sexually abused children.

For the purpose of this study, only children with a nonoffending parent or caregiver (e.g., stepparent, foster parent, grandparent) participating in treatment were considered. The following criteria were required to be included in this study: (a) the child was between 7 and 16 years of age, and (b) Child Protective Services investigated the sexual abuse allegation and determined it to be founded. If two caregivers were participating in treatment, data only from the primary caregiver was utilized. In a few instances where there were two caregivers of a child participating in treatment, the primary caregiver was identified either by having the closest biological relationship to the child or was based on which caregiver the child lived with or spent the most time with. There were no restrictions regarding the gender of the victim, nonoffending parent, or the perpetrator. Also, there was no restriction applied to the relationship between the victim and alleged perpetrator (i.e., intrafamilial versus extrafamilial). To be included in Project SAFE services, parents and children must not have denied that the abuse occurred or had significant impairment in cognitive/intellectual functioning or severe psychopathology.

\section{Parent-Report Measures}

\section{Demographic Questionnaire}

The Demographic Questionnaire was designed specifically for this study to collect general information about the family members. Information about the 
responding parent(s) included relationship status, ethnic background, employment status, family income, highest level of education attained, and age. Information about the child included age, ethnic background, and current grade in school.

\section{Child History Form}

The Child History Form (CHF) is an unstructured interview that collected relevant abuse-related information. The CHF was completed by one of the Project SAFE staff members while parents verbally provided information about the abuse in their own words. Abuse characteristics gathered include age at onset and cessation of abuse, abuse duration, relationship to perpetrator, frequency of abuse, nature of abuse, and severity of abuse.

\section{Child Behavior Checklist}

The Child Behavior Checklist (CBCL; Achenbach, 1991) Parent Report Form is a 113-item checklist assessing parents' perceptions of behavioral problems and social competence of their children. It is designed for use with parents of children ages 4-18. Parents are asked to rate the presence of problem behaviors in the previous six months on a three-point scale ranging from 0 (not true) to 2 (very true or often true). The CBCL includes behavior problem scales that vary according to children's ages and gender. It consists of nine symptom scales: social withdrawal, somatic complaints, anxiety/depression, social problems, thought problems, attention problems, delinquent behavior, aggressive behavior, and sex problems. There are also two broad groupings of symptoms measured by the CBCL: internalizing behaviors (includes the social withdrawal, somatic complaints, and anxiety/ depression scales) and externalizing behavior (includes the aggressive behavior and delinquent behavior scales). In addition, a total problem score can be calculated by summing the scores for each item on the CBCL. Finally, the CBCL includes a social competence measure that is separated into activities, school, and social subscales. The CBCL is a widely used instrument with well-established reliability and validity (Achenbach), with scales standardized for age and gender.

\section{Parental Expectancies Scale}

The Parental Expectancies Scale (PES) is a 13-item inventory wherein parents rate the expectations they have for their child's functioning (e.g., school performance, peer relationships, family functioning, emotional adjustment) over the next 12 months as compared to peers. Scores are rated on a 10-point scale ranging from 1 (much worse than most other children) to 10 (much better than 
most other children). For example, parents are asked to rate how they expect their child compares to other children his or her age on making new friends, adjusting emotionally, and following rules at home. The PES was developed by Project SAFE and has been used only with nonoffending parents participating in treatment services provided by Project SAFE. As a newly developed measure, this inventory does not yet consist of any subscales and consequently, individual item scores and the total sum score were examined. Notably, for the purposes of the present study, item 13 (i.e., "fighting with other children") was omitted from all analyses due to its poor internal consistency, which is likely a result of the awkward phrasing of the item. On the 12 remaining individual PES questions, pre- and posttreatment scores ranged from 1 to 8 on four items, from 1 to 9 on five items, and 1 to 10 on three items. In addition, the pretreatment total sum score ranged from 18 to 94 , and the posttreatment total sum score from 26 to 96. Responses on the PES were reverse scored for the purposes of this study; thus, high scores on the PES indicate lower or poorer parental expectations. Preliminary analyses on all 67 participants in this study suggest a high degree of internal consistency $(\alpha=.93)$.

\section{Post Sexual Abuse Expectations Scale}

The Post Sexual Abuse Expectations Scale (PSAES), also developed for and used by Project SAFE participants, is an 8-item inventory on which parents rate the negative impact they expect sexual abuse to have on their child over the next 12 months on a S-point scale ranging from 1 (no negative impact) to 5 (substantial negative impact). Domains of impact include school; peer relationships; relationships with the parent, other caregivers, and siblings; behavioral and emotional adjustment; and overall future functioning. As with the PES, this inventory does not yet consist of any subscales and as such, individual item scores and the total sum score were examined. Responses to pretreatment individual items ranged from 1 to 4 on one item and from 1 to 5 on the remaining seven; total sum scores ranged from 8 to 34.5. At posttreatment, PSAES scores ranged from 1 to 4 on five items and 1 to 5 on three items, with the total sum score ranging from 8 to 31 . High scores on the PSAES indicate lower or poorer parental expectations. Preliminary analyses on all 67 participants in this study suggest a high degree of internal consistency $(\alpha=.90)$.

\section{Child-Report Measures}

\section{Children's Depression Inventory}

The Children's Depression Inventory (CDI; Kovacs, 1992) is a 27-item selfreport measure that assesses depression in children ages 7 to 17. Children are 
asked to endorse statements reflecting the cognitive and somatic symptoms of depression. Respondents are instructed to rate how they felt in the past two weeks based on three choices that are keyed from 0 to 2, with higher scores indicating higher symptom severity. This measure has been found to be reliable, with internal consistency ranging from .71 to .89 . Test-retest reliability has also been established (.72 to .84). T-score norms are available for boys and girls separately ages 7 to 12 and 13 to 17 .

\section{Revised Children's Manifest Anxiety Scale}

The Revised Children's Manifest Anxiety Scale (RCMAS; Reynolds \& Richmond, 1985) is a 37-item self-report measure that assesses general anxiety in children and adolescents ages 6 to 19. Respondents are asked to circle "yes" or "no" responses to each item. The total anxiety score is based on 28 items pertaining to physiological, subjective, and motor symptoms of anxiety. Reliability has been established with the RCMAS $(\alpha=.83)$.

\section{Intervention}

Project SAFE is a curriculum-led group treatment program for sexually abused youths (ages 7 to 16) and their nonoffending parents or caregivers (Hansen, Hecht, \& Futa, 1998). Separate youth and parent groups, both of which covered parallel topics, were cofacilitated by doctoral students (supervised by licensed clinical psychology faculty) in the Clinical Psychology Training Program at the University of Nebraska-Lincoln. Youth and parent groups each met for 90-minute sessions for 12 consecutive weeks. There were 11 treatment modules covered throughout the course of therapy: Welcome and Orientation, Understanding and Recognizing Feelings, Learning about Our Bodies, Standing Up for Your Rights, My Family, Sharing What Happened to Me Part I and II (2 sessions), Understanding My Feelings about What Happened to Me, Learning to Cope with My Feelings Parts I and II (2 sessions), and Summary and Good-Bye.

Recent evaluations have examined child and family outcomes and social validity for the Project SAFE intervention (e.g., Hsu, 2003; Hsu, Sedlar, Flood, \& Hansen, 2002; Sawyer et al., 2005). Results demonstrate posttreatment improvements in child behavior and functioning per parent report. Children also reported decreased anxiety, posttraumatic stress symptoms, maladaptive abuse attributions, negative perceptions of social reactions, and increased basic sexual knowledge after treatment. In general, treatment gains were maintained three months after completion. Subjective evaluations by parent and child participants revealed that treatment goals, procedures, and outcomes were acceptable, relevant, and helpful to the families. 


\section{Procedures}

\section{Participant Recruitment}

Families participating in Project SAFE learned about the treatment program through local services such as a child advocacy center, Child Protective Services, and mental health providers and agencies. Families who met the inclusion criteria and who were interested in participating were scheduled for a pretreatment assessment. Families were informed that assessments would be completed a total of four times to demonstrate progress made during treatment. They were also informed that they would receive $\$ 20.00$ for completing each of the assessments. If the parents did not attend the parents' group, the family was given a packet to complete and return to the program director. Regardless of research participation, Project SAFE treatment was offered as a free service to all participating families.

\section{Informed Consent And Confidentiality}

Once families began participating in Project SAFE (i.e., attending the pretreatment assessment session), they were considered clients of the Psychological Consultation Center (PCC), a training clinic for the Clinical Psychology Training Program at the University of Nebraska-Lincoln. As such, paperwork and procedures consistent with PCC policy (e.g., consent forms, limits of confidentiality, and supervision for Project SAFE therapists) were completed for each participating family member. Although families could participate in Project SAFE and agree not to be a part of the research project, no families refused.

\section{Assessment}

All assessment measures used in the present study were part of a larger battery of assessments. Family members participating in Project SAFE were asked to complete a pretreatment assessment, a midtreatment assessment after six weeks, a posttreatment assessment, and a follow-up assessment about two to three months after termination of therapy. For the present study, only the pretreatment and posttreatment assessments were used. Assessment batteries took 1.5 to 2 hours to complete for both parent and child. Parents and children com-

pleted the assessment batteries in separate rooms. The order of administration of the measures was not anticipated to influence the results obtained on the various measures. 


\section{Results}

\section{Demographic Information}

\section{Nonoffending Parents}

The mean age of the 63 nonoffending parent participants was 37.33 years $(S D=6.58$, range: $23-60)$. The majority of nonoffending caregivers were biological mothers $(64.2 \%)$ and White $(77.6 \%)$. Most of the parents were also employed (73.1\%) and about half were married (49.2\%). Fifty-nine parents had one child participating in Project SAFE, and four parents had two children who were participants.

\section{Victims}

Sixty-seven children completed pretreatment assessments. As reported by parents, children's mean age was 11.51 years $(S D=2.79$, range: $6.92-16.33)$. The sample included 43 (64.2\%) school-age children (ages 7-12) and 24 (35.8\%) adolescents (ages 13-17). Fifty-one children (76.1\%) were girls and 16 (23.9\%) were boys. Regarding racial identity, 52 (77.6\%) were White, 7 00.4\%) were African American, $10.5 \%$ ) was Hispanic American, 1 (1.5\%) was Native American, 4 $(6.0 \%)$ were biracial, and $2(3.0 \%)$ were of mixed race.

Forty-four children, who ranged in age from 7.17 to 16.08 years $(M=11.73$, $S D=2.66)$, completed posttreatment assessments. The sample included 26 (59.1\%) school age-children (ages 7-12) and 18 (40.9\%) adolescents (ages 13-17). Thirty-seven children (84.1\%) were girls and 7 05.9\%) were boys. Regarding racial identity, 35 (79.5\%) were White, 4 (9.1\%) were African American, 3 (6.8\%) were biracial, and $2(4.5 \%)$ were of mixed race.

\section{Abuse Characteristics}

Most of the children in this study were abused by one perpetrator $(n=58$; $86.6 \%)$. Eight $(11.9 \%)$ victims had two perpetrators and one $(1.5 \%)$ victim had three perpetrators. For the 67 children, information regarding the abuse was available for all 77 perpetrators. There were 75 (97.4\%) male and two (2.6\%) female perpetrators. Information regarding the perpetrators' relationship to the child and abuse characteristics, including sexual abuse behaviors and use of force, for both pretreatment and posttreatment samples are summarized in Table 1 and Table 2 respectively. Within the larger, pretreatment sample, the majority of victims experienced some form of contact abuse, with fondling the most common sexual abuse behavior. According to reports made by nonoffending parents, the mean age at which the abuse began was $9.10(S D=2.84$, range 4-15), and the mean age at which the abuse ended for the 62 victims was 10.13 
$(S D=2.84$, range 4-15). The duration of the abuse ranged from 0 to 90 months, with a mean duration of 12.33 months $(S D=19.04)$.

Regarding abuse discovery, nonoffending parents indicated that the majority of child victims either made a report to a parent, a peer, or another adult

Table 1. Alleged Perpetrator's Relationship to the Child

\begin{tabular}{|c|c|c|c|c|}
\hline \multirow{2}{*}{$\begin{array}{l}\text { Demographic } \\
\text { Characteristics }\end{array}$} & \multicolumn{2}{|c|}{$\begin{array}{c}\text { Pretreatment } \\
\text { Youth } \\
(N=77)\end{array}$} & \multicolumn{2}{|c|}{$\begin{array}{c}\text { Posttreatment } \\
\text { Youth } \\
(N=50)\end{array}$} \\
\hline & $N$ & $(\%)$ & $N$ & $(\%)$ \\
\hline Biological parent & 10 & 13.0 & 5 & 10.0 \\
\hline Stepparent & 3 & 3.9 & 3 & 6.0 \\
\hline Parent's boyfriend/girlfriend & 10 & 13.0 & 8 & 16.0 \\
\hline Sibling & 10 & 13.0 & 6 & 12.0 \\
\hline Grandparent & 3 & 3.9 & 3 & 6.0 \\
\hline Other family member & 10 & 13.0 & 9 & 18.0 \\
\hline Adult family friend & 4 & 5.2 & 2 & 4.0 \\
\hline Child family friend & 8 & 10.4 & 4 & 8.0 \\
\hline Neighbor & 10 & 13.0 & 5 & 10.0 \\
\hline Stranger & 3 & 3.9 & 2 & 4.0 \\
\hline Peer & 6 & 7.8 & 3 & 6.0 \\
\hline
\end{tabular}

Due to some victims having multiple perpetrators, the number of perpetrators exceeds the number of youth in this study.

Table 2. Abuse Characteristics

\begin{tabular}{lrrrr}
\hline & \multicolumn{2}{c}{ Pretreatment } & \multicolumn{2}{c}{ Posttreatment } \\
Abuse Characteristics & $N$ & $(\%)$ & $N$ & $(\%)$ \\
\hline Sexual Abuse Behaviors & & & & \\
Unknown & 1 & 1.5 & 0 & 0.0 \\
Exposure (by perpetrator) & 16 & 23.9 & 12 & 27.3 \\
Viewing pornography & 6 & 9.0 & 5 & 11.4 \\
Fondling & 47 & 70.1 & 31 & 70.5 \\
Anal intercourse & 5 & 7.5 & 3 & 6.8 \\
Oral contact (abuser to child's genitals & 16 & 23.9 & 8 & 18.2 \\
$\quad$ or child to abuser's genitals) & & & & \\
Vaginal intercourse & 10 & 14.9 & 8 & 18.2 \\
Digital penetration & 7 & 10.4 & 6 & 13.6 \\
Child performing acts on another & 2 & 3.0 & 1 & 2.3 \\
$\quad$ person (excluding offender) & & & & \\
Use of Force to Gain Compliance or Secrecy & & & & \\
Unknown & 26 & 38.8 & 13 & 29.5 \\
Yes & 13 & 19.4 & 10 & 22.7 \\
No & 28 & 41.8 & 21 & 47.8 \\
\hline Dito & & & & \\
\hline
\end{tabular}

Due to multiple forms of sexual abuse that were experienced by the victims, the percentages do not add up to 100. 
$(n=48 ; 71.6 \%)$. Other methods of disclosure included another family member making a report $(n=8 ; 11.9 \%)$; perpetrator disclosing $(n=2 ; 3.0 \%)$; perpetrator being caught $(n=1 ; 1.5 \%)$; physical evidence $(n=1 ; 1.5 \%)$; child acted out sexually, leading to an investigation of sexual abuse $(n=1 ; 1.5 \%)$; or other $(n$ $=4 ; 6.0 \%)$. Two $(3.0 \%)$ nonoffending parents did not know the abuse disclosure information. Police were involved with 62 (92.5\%) of the children. Thirtysix $(53.7 \%)$ children had been abused within six months of the interview, while $25(37.3 \%)$ had been abused more than six months prior to the interview. The duration between the end of the abuse and the interview was unknown for 6 $(9.0 \%)$ children.

\section{Relationship of Pretreatment Parental Expectations Scores and Pretreatment Children's Functioning Scores}

Pearson's correlations were computed among scores on the CDI, RCMAS, Internalizing Problems Scale on CBCL, Externalizing Problems Scale on CBCL, Total Problems Scale on CBCL, PES Total, PSAES Total, resulting in 21 correlational values. Scores on the PES were significantly correlated with scores on the CDI, $r=.268, p<.05$, and the Total Problems Scale on the CBCL, $r=.271, p<.05$, but not the Internalizing or Externalizing Problems Scales on the CBCL or the RCMAS. Scores on the PSAES were significantly and positively associated with scores on the Internalizing $(r=.280, p<.05)$, Externalizing $(r=.366, p<.01)$, and Total $(r=.326, p<.01)$ Problems Scales on the CBCL. There was no association found between scores on the PSAES and the CDI or RCMAS.

A series of multiple regression analyses were conducted. The first, with CBCL Internalizing Problems Scale scores as the criterion variable and total scores on the PES and PSAES as the predictor variables, was significant, $R^{2}=$ $.094, F(1,65)=3.31, p<.05$. However, neither parental expectations nor parental sexual abuse expectations contributed to this multivariate model (see Table 3). When the criterion variable was CBCL Externalizing Problems Scale scores and total scores on the PES and PSAES were predictors, the resulting $R^{2}=.172$ was significant, $F(1,65)=6.654, p<.01$. There was a significant positive relationship between parental sexual abuse expectations and children's externalizing problems after taking parental expectations into account. However, parental expectations did not contribute to this model (see Table 3). Finally, when the criterion variable was CBCL Total Problems Scale scores and PES and PSAES total scores were predictors, the resulting $R^{2}=.164$ was significant, $F(1,65)=6.282, p<.01$. There was a significant positive relationship between parental sexual abuse expectations and children's total behavior problems. Again, after taking parental expectations into account, parental expectations did not contribute to this model. 
Table 3. Regression Analysis Summary for Parental Expectations Measures (Pretreatment) Predicting Children's Internalizing Problems Scale, Externalizing Problems Scale, and Total Problems Scale on CBCL (Pretreatment)

\begin{tabular}{lccll}
\hline Measure & $B$ & SEB & $\beta$ & $R^{2}$ \\
\hline Internalizing & & & & \\
PES Total & .120 & .077 & .196 & \\
PSAES Total & .378 & .262 & .181 & $.094^{*}$ \\
Externalizing & & & & \\
PES Total & .009 & .079 & .141 & \\
PSAES Total & .780 & .269 & $.348^{* *}$ & $.172^{* *}$ \\
Total & & & & \\
PES Total & .130 & .077 & .204 & \\
PSAES Total & .634 & .262 & $.291^{*}$ & $.164^{* *}$ \\
\hline
\end{tabular}

${ }^{*} p<.05 ;{ }^{* *} p<.01$

\section{Relationship of Pretreatment Parental Expectations Scores and Posttreatment Children's Functioning Scores}

Pearson's correlations were computed among scores on the CDI, RCMAS, Internalizing Problems Scale on CBCL, Externalizing Problems Scale on CBCL, Total Problems Scale on CBCL, PES Total, and PSAES Total, which resulted in 21 correlational values. Pretreatment total scores on the PES were not correlated with posttreatment scores on the CDI, RCMAS, or the Internalizing, Externalizing, or Total Problems Scales on the CBCL. Scores on the PSAES were significantly positively associated with scores on Internalizing $(r=.401, p<.01)$, Externalizing $(r=.370, p<.05)$, and Total $(r=.398, p<.01)$ Problems Scales on the CBCL. No association was found between scores on the PSAES and the CDI or RCMAS.

Because symptom expression can vary over time and as a result of treatment, changes in children's functioning between pre- and posttreatment were examined. Paired $t$-tests of pre-post measures suggested that children reported decreases in both depression and anxiety. Parents also reported their children experiencing decreases in overall behavioral problems (see Table 4).

A hierarchical (nested) multiple regression analysis was conducted to determine how well pretreatment parental expectations of children's functioning predicts posttreatment children's internalizing problems. Using posttreatment scores on the CBCL Internalizing Problem Scale as the criterion variable, pretreatment scores on the CBCL Internalizing Problems Scale were entered in the first block and total pretreatment scores were entered on the PSAES in the second block. Results indicated that in the initial step pretreatment CBCL Internalizing Problems scores were predictive of posttreatment CBCL Internalizing Problems scores, $F(1,42)=43.57, p<.001$. In the second step, to- 
Table 4. Changes in Children's Mental Health Functioning Between Pre- and Posttreatment

\begin{tabular}{lcrllll}
\hline & \multicolumn{2}{c}{ Pretreatment } & & \multicolumn{2}{l}{ Posttreatment } & \\
\cline { 2 - 3 } Mental Health Measure & $M$ & $S D$ & & $M$ & $S D$ & \\
\hline CDI Total & 54.00 & 12.99 & & 47.47 & 10.42 & $3.807^{* *}$ \\
RCMAS Total & 55.00 & 12.58 & & 47.46 & 12.12 & $4.686^{* *}$ \\
CBCL Total Problems Scale & 61.23 & 10.96 & & 59.07 & 11.39 & $2.134^{*}$ \\
Internalizing Problems & 62.57 & 9.83 & & 58.64 & 10.72 & $3.234^{* *}$ \\
Externalizing Problems & 60.14 & 11.01 & & 59.14 & 10.82 & 1.073 \\
\hline
\end{tabular}

${ }^{*} p<.05 ;{ }^{* *} p<.01$

Table 5. Summary of Hierarchical Multiple Regressions with CBCL Internalizing Problems Scale, Externalizing Problems Scale, and Total Problems Scale (Posttreatment) as the Criterion Variables

\begin{tabular}{lllll}
\hline Step and Variable & $\beta$ In & $\beta$ Final & $R^{2}$ & \multicolumn{1}{c}{$\Delta R^{2}$} \\
\hline Internalizing Problems Scale & & & & \\
1. CBCL Internalizing Problems Scale (Pretreatment) & $.714^{* *}$ & $.656^{* *}$ & $.509^{* *}$ & $.509^{* *}$ \\
2. PSAES Total Score (pretreatment) & .164 & $.533^{* *}$ & .024 & \\
Externalizing Problems Scale & & & & \\
1. CBCL Internalizing Problems Scale (Pre-Treatment). & $.853^{* *}$ & $.843^{* *}$ & $.727^{* *}$ & $.727^{* *}$ \\
2. PSAES Total Score (pretreatment) & .023 & $.728^{* *}$ & .001 & \\
Total Problems Scale & & & & \\
1. CBCL Internalizing Problems Scale (Pretreatment) & $.821^{* *}$ & $.791^{* *}$ & $.673^{* *}$ & $.673^{* *}$ \\
2. PSAES Total Score (pretreatment) & .073 & $.678^{* *}$ & .004 & \\
\hline
\end{tabular}

${ }^{*} p<.05 ;{ }^{* *} p<.01$

tal pretreatment scores on the PSAES did not contribute significantly to the model over the contribution of pretreatment CBCL Internalizing Problems scores (see Table 5).

A hierarchical (nested) multiple regression analysis was then conducted to determine how well pretreatment parental expectations of children's functioning predicts posttreatment externalizing problems. Using posttreatment scores on the CBCL Externalizing Problem Scale as the criterion variable, pretreatment scores on the CBCL Externalizing Problems Scale were entered in the first block and total pretreatment scores were entered on the PSAES in the second block. Results indicated that in the initial step of the analysis, pretreatment CBCL Externalizing Problems scores were predictive of parental expectations, $F(1,42)=$ 111.97, $p<.001$. In the second step, total pretreatment scores on the PSAES did not contribute significantly to the model over the contribution of pretreatment CBCL Externalizing Problems scores (see Table 5).

A third hierarchical (nested) multiple regression analysis was conducted to determine how well pretreatment parental expectations of children's function- 
ing predicts posttreatment behavior problems. Using posttreatment scores on the CBCL Total Problem Scale as the criterion, variable pretreatment scores on the CBCL Total Problems Scale were entered in the first block and total pretreatment scores were entered on the PSAES in the second block. Results indicated that in the initial step of the analysis pretreatment CBCL Total Problems scores were predictive of posttreatment CBCL Total Problem Scale scores, F(1, $42)=86.55, p<.001$. In the second step, total pretreatment scores on the PSAES did not contribute significantly to the model over the contribution of pretreatment CBCL Total Problems scores (see Table 5).

\section{Discussion}

Although much of the research on factors contributing to CSA outcomes has focused on variables that cannot be targeted in treatment (e.g., demographic characteristics), research more recently has focused on mediating factors that can be addressed through therapy (e.g., coping and attributional styles; Steel, Sanna, Hammond, Whipple, \& Cross, 2004). As part of the effort toward investigating factors that may be more amenable to intervention, this study focused on how parental expectations may impact sexually abused children's functioning. Negative parental expectations may have a detrimental impact on CSA victims in addition to the negative effects of the abuse experience itself. As such, this study makes a contribution to the very limited research addressing the relationship between parental expectations and CSA.

The first goal of this study was to examine the impact of parental expectations to account for variance in children's emotional and behavioral functioning as children presented for treatment. Poorer parental expectations of how sexual abuse would affect their children were associated with overall behavior problems in children, as well as a variety of parent-rated internalizing and externalizing behavior problems. These expectations were generally not associated with children's self-report of internalizing symptoms. This suggests that parental expectations are more closely associated with their perceptions of children's current functioning than how children perceive their own mental health functioning. Consistent with the self-fulfilling prophecy effect, it is possible that the child's CSA label influences parents to anticipate and perceive mental health problems in their sexually abused children, even if the child does not endorse such difficulties.

Considered together, parental expectations about children's future functioning and parental expectations about the impact sexual abuse will have on children were good predictors of parent-reported overall behavior problems in children and of both externalizing and internalizing behavior problems. Parental sexual abuse expectations were also a good predictor of externalizing and 
total behavior problems, but not of internalizing behavior problems. This finding is likely due to the PSAES consisting almost entirely of externalizing behavior items. Surprisingly, parental expectations of children's future functioning did not predict children's behavior problems. These results suggest that parental expectations about how sexual abuse will impact their children are a better predictor than parental expectations of children's global future functioning. Overall, it appears that how much parents identify with the label of sexual abuse plays an important role in influencing parents' ratings and perceptions of children's behavior.

The second goal of this study was to investigate the ability of parental expectations at pretreatment to account for variance in children's emotional and behavioral functioning at posttreatment. No relationship was found between pretreatment PES scores and any of the posttreatment child mental health measures. However, pretreatment PSAES scores were correlated with parent-reported child behavior problems but not with results from child self-report measures. Hence, parental expectations of how sexual abuse will affect their children were not related to children's posttreatment ratings of depression or anxiety. Pretreatment PSAES scores were predictive of posttreatment scores on parent-report measures of children's behavior; however, pretreatment PES scores did not have this predictive relationship.

Based on these results, it is interesting that general parental expectancies of children's future functioning were not predictive of children's functioning scores, either at pretreatment or posttreatment, yet parental expectations of how sexual abuse will affect children were predictive of children's functioning scores at pretreatment and were associated with children's functioning scores at posttreatment. These results highlight the influential role the sexual abuse label has on shaping parental perceptions about children's functioning.

The results of this study are important not only because they shed light on the long-term impact parental expectations of CSA have on their perceptions of children's functioning, but also because results showed that children's mental health symptoms, as rated by children and parents, decreased from pre- to posttreatment. This change suggests that the Project SAFE treatment program was effective in reducing children's psychopathology. Perhaps, then, other cognitive-behavioral group treatment programs for nonoffending caregivers and sexually abused children can also have a substantial role in facilitating children's recovery.

\section{Limitations}

In contrast to studies measuring the perceptions of college students or professionals engaged in service delivery, the current study extends the literature by measuring parental expectations of children's recovery from CSA in a sample of nonoffending caregivers and their sexually abused youth. There are, 
however, several methodological limitations that warrant consideration. First, the sample was rather ethnically homogeneous, limiting generalizability of the results to more ethnically diverse parent and youth dyads. In light of descriptive findings highlighting the impact of cultural factors on mothers' reactions to CSA disclosure (e.g., Alaggia, 2001), it is quite possible that parental expectancies and youths' outcomes will vary in ethnically diverse families. In addition, as all participants in the current study acknowledged CSA and were members of a treatment group for sexual victimization, the external validity of our findings is limited to treatment-seeking families. It may be that families' disclosure of CSA and participation in treatment playa critical role in shaping parental expectations and children's functioning, with different patterns emerging in families that (a) do not acknowledge CSA, even though it is suspected or indicated, or (b) do not seek treatment, in spite of CSA disclosure.

Another limitation involves the use of the PES and PSAES, two measures that assess parental expectations. Both of these instruments, which were designed for Project SAFE, have been used only in this study and do not yet consist of subscales. Consequently, analyses relied primarily on the use of total scores. Although these analyses demonstrated that the PES and PSAES have internal consistency and content validity, knowledge of additional psychometric properties is limited. The use of a parental expectations scale that has both normative data and several subscales could potentially provide more informative results. In addition, because the PSAES largely identifies externalizing rather than internalizing symptoms, a revision of the PSAES to include a more balanced inventory of internalizing and externalizing symptom questions is warranted. Finally, because this study used correlation and regression analyses, causal relationships and interpretations cannot be gleaned. Although our design involved pre- and posttreatment assessments, future longitudinal studies are required in order to generate causal conclusions. In spite of these limitations, the current study not only filled a gap in the literature by examining parental expectations of their sexually abused children but also utilized a sound methodological framework, which included a multi-informant, longitudinal design.

\section{Conclusions and Recommendations}

Understanding how parents' beliefs and expectations influence children's recovery from sexual abuse has important research implications. Our results reveal that parental expectations are a strong predictor of parents' ratings of children's functioning regardless of emotional and behavioral symptomatology reported by the child. In light of these findings, it may be useful to pose additional research questions (e.g., Do parents' expectations predict children's actual symptomatology in the immediate or long-term aftermath of CSA? Do children's expectations about their own functioning relate to their current mental 
health symptoms or to their parents' expectations?). Further research is also needed to examine additional constructs related to CSA effects. For instance, one potentially important variable is the nonoffending parents' own abuse history. Not only has research shown that mothers who endorse past sexual abuse are more likely to have children (daughters, in particular) who experience CSA (e.g., McCloskey \& Bailey, 2000), these parents' expectancies of their sexually abused children's functioning may be based largely on their personal abuse histories (e.g., severity of their own abuse experience, support [or lack thereof] received from others). Another variable that may influence parents' expectations and attitudes as well as children's outcomes and functioning is the perpetrator's relationship to the child and nonoffending parent (e.g., intrafamilial versus extrafamilial; stranger versus acquaintance; Holguin \& Hansen, 2003).

As discussed, adults' often negativistic assumptions about sexually abused children's current functioning and future prognosis may shape adult-child interactions across a variety of settings and engender self-fulfilling prophecies in the abused child (e.g., Briggs et al., 1995; Holguin \& Hansen, 2003; Kouyoumdjian et al., 2005), These findings collectively inform clinical interventions for CSA survivors. In addition to supporting the use of family-based treatments (Cohen \& Mannarino, 1996, 1998, 2000; Deblinger, Lippman, \& Steer, 1996), this research corroborates Swenson and Chaffin's (2006) recommendation to consider additional "social ecological" systems (e.g., community and peer influences) that may impact CSA victims' recovery. Rather than utilizing a "more is better" or "shotgun" conceptualization, the authors advocate conducting multisystemic assessments with abuse victims and incorporating "core, central, relevant" ecological influences into individualized treatment plans (p. 127). Additionally, these findings highlight the need to implement interventions that (a) provide psychoeducation to children, parents, and professionals about the documented correlates (as well as maintaining or attenuating factors) associated with CSA; (b) encompass a strengths-based approach (e.g., by encouraging the child to engage in rewarding activities or helping parents provide optimal support to their sexually abused child); and (c) address adults' negative expectancies by, for example, teaching adults to pay attention to their biases and behaviors on an ongoing basis (e.g., Briggs et al., 1994, 1995; Bromfield et al., 1988; Cohen \& Mannarino, 2000; Ford et al., 2001; Hetherton \& Beardsall, 1998; Holguin \& Hansen, 2003; Kouyoumdjian et al., 2005; Saathoff-Wells et al., 2005; Spaccarelli \& Kim, 1995), Together, these research and clinical efforts will help promote more successful recovery in youth who have been sexually abused.

\section{References}

Achenbach, T. M. (1991). The child behavior checklist manual. Burlington, VT: The University of Vermont. 
Adams-Tucker, C. (1982). Proximate effects of sexual abuse in childhood: A report on 28 children. American Journal of Psychiatry, 139, 1252-1256.

Alaggia, R. (2001). Cultural and religious influences in maternal response to intrafamilial child sexual abuse: Charting new territory for research and treatment. Journal of Child Sexual Abuse, 10, 41--60.

Beitchman, J. H, Zucker, K. J., Hood, J. E., DaCosta, G. A., Akman, D., \& Cassavia, E. (1992). A review of the long-term effects of child sexual abuse. Child Abuse and Neglect, 16, 101-118.

Briggs, K, Hubbs-Tait, L., Culp, R. E., \& Blankemeyer, M. (1995). Perceiver bias in expectancies for sexually abused children. Family Relations, 44, 291-298.

Briggs, K., Hubbs-Tait, L., Culp, R. E., \& Morse, A. S. (1994). Sexual abuse label: Adults' expectations for children. The American Journal of Family Therapy, 22, 304-314.

Bromfield, R., Bromfield, D., \& Weiss, B. (1988). Influence of the sexually abused label on perceptions of a child's failure. Journal of Educational Research, 82, 96-98.

Clark, M. D., \& Artiles, A. J. (2000). A cross-national study of teachers' attributional patterns. Journal of Special Education, 34, 77-89.

Cohen, J. A., \& Mannarino, A. P. (1996). Factors that mediate treatment outcome of sexually abused preschool children. Journal of the American Academy of Child and Adolescent Psychiatry, 35, 1402-1410.

Cohen, J. A., \& Mannarino, A. P. (1998). Factors that mediate treatment outcome of sexually abused preschool children: Six- and 12-month follow-up. Journal of the American Academy of Child and Adolescent Psychiatry, 37, 44-51.

Cohen, J. A., \& Mannarino, A. P. (2000). Predictors of treatment outcome in sexually abused children. Child Abuse and Neglect, 24, 983-994.

Deblinger, E., Lippmann, J., \& Steer, R. (1996). Sexually abused children suffering posttraumatic stress symptoms: Initial treatment outcome findings. Child Maltreatment, 1, 310-321.

DiLillo, D. (2001). Interpersonal functioning among women reporting a history of childhood sexual abuse: Empirical findings and methodological issues. Clinical Psychology Review, 21, 553-576.

Dollar, K. M., Perry, A. R., Fromuth, M. E., \& Holt, A. R. (2004). Influence of gender roles on perceptions of teacher/adolescent student sexual relations. Sex Roles: A Journal of Research, 50, 91-101.

Ford, H. H., Schindler, C. B., \& Medway, F. J. (2001). School professionals' attributions of blame for child sexual abuse. Journal of School Psychology, 39, 25-44.

Freund, J. H., Bradley, R. H., \& Caldwell, B. M. (1979). The home environment in the assessment of learning disabilities. Learning Disability Quarterly, 2, 39-51.

Guelzow, J. W., Cornett, P. F., \& Dougherty, T. M. (2002). Child sexual abuse victims' perception of paternal support as a significant predictor of coping style and global selfworth. Journal of Child Sexual Abuse, 11, 53-72.

Guttmann, J., \& Broudo, M. (1988/1989). The effect of children's family type on teachers' stereotypes. Journal of Divorce, 12, 315-328.

Hansen, D. J., Hecht, D. B., \& Futa, K. T. (1998). Child sexual abuse. In V. B. Van Hasselt \& M. Hersen (eds.), Handbook of psychological treatment protocols for children and adolescents (pp. 153-178). Hillsdale, NJ: Lawrence Erlbaum Associates, Inc. 
Hetherton, J., \& Beardsall, L. (1998). Decisions and attitudes concerning child sexual abuse: Does the gender of the perpetrator make a difference to child protection professionals? Child Abuse and Neglect, 22, 1265-1283.

Hicks, C., \& Tite, R. (1998). Professionals' attitudes about victims of child sexual abuse: Implications for collaborative child protection teams. Child and Family Social Work, 3, 37-48.

Holguin, G., \& Hansen, D. J. (2003). The "sexually abused child": Potential mechanisms of adverse influences of such a label. Aggression and Violent Behavior, 8, 645-670.

Holm, J. W., Holguin, G., \& Hansen, D. J. (2002, November). Influences of the "sexual abuse" label on expectancies among professionals working with children: Implications for treatment and further research. Poster presented at the Association of Behavior Therapy, Reno, Nevada.

Hsu, E. (2003). Parallel group treatment for sexually abused children and their nonoffending parents: An examination of treatment integrity and child and family outcome and satisfaction. PhD dissertation, University of Nebraska-Lincoln.

Hsu, E., Sedlar, G., Flood, M. F., \& Hansen, D. J. (2002). Child sexual abuse. In M. Hersen (ed.), Clinical behavior therapy: Adults and children (pp. 449-473). New York: John Wiley and Sons.

Jussim, I., Eccles, J., \& Madon, S. (1996). Social perception, social stereotypes, and teacher expectations: Accuracy and the quest for the powerful self-fulfilling prophecy. In M. P. Zanna (ed.), Advances in experimental social psychology (pp. 281-388). San Diego, CA: Academic Press.

Kendall-Tackett, K. A., Williams, L. M., \& Finkelhor, D. (1993). Impact of sexual abuse on children: A review and synthesis of recent empirical studies. Psychological Bulletin, 113, 164-180.

Kouyoumdjian, H., Perry, A. R., \& Hansen, D. (2005). The role of adult expectations on the recovery of sexually abused children. Aggression and Violent Behavior, 10, 475-489.

Kovacs, M. (1992). Children's depression inventory. Toronto, Canada: Multi-Health Systems.

Madon, S., Jussim, L., \& Eccles, J. (1997). In search of the powerful self-fulfilling prophecy. Journal of Personality and Social Psychology, 72, 791-809.

Maynard, C., \& Wiederman, M. (1997). Undergraduate students' perceptions of child sexual abuse: Effects of age, sex, and gender-role attitudes. Child Abuse \& Neglect, 21, 833-844.

McCloskey, L. A., \& Bailey, J. A. (2000). The intergenerational transmission of risk for child sexual abuse. Journal of Interpersonal Violence, 15, 1019-1035.

Morrison, N. C., \& Clavenna-Valleroy, J. (1998). Perceptions of maternal support as related to self-concept and self-report of depression in sexually abused female adolescents. Journal of Child Sexual Abuse, 7, 23-40.

Paolucci, E. O., Genuis, M. L., \& Violato, C. (2001). A meta-analysis of the published research on the effects of child sexual abuse. Journal of Psychology, 135, 17-36.

Polusny, M. A., \& Follette, V. M. (1995). Long-term correlates of child sexual abuse: Theory and review of the empirical literature. Applied and Preventive Psychology, 4, 143-166.

Putnam, F. W. (2003). Ten-year research update review: Child sexual abuse. Journal of the American Academy of Child and Adolescent Psychiatry, 42, 269-278.

Reynolds, C. R., \& Richmond, B. O. (1985). Revised children's manifest anxiety scale manual. Los Angeles: Western Psychological Services. 
Saathoff-Wells, T., Culp, R. E., \& Yancey, C. T. (2005). Expectancies for sexually abused children: Evidence of perceiver bias. Journal of Child and Family Studies, 14, 487-503.

Sawyer, G. K., Yancey, C. T., Tsao, E. H., Wynne, A., Hansen, D. J., \& Flood, M. F. (2005, November). Parallel group treatments for sexually abused youth and their nonoffending parents: Treatment integrity, outcomes, and social validity of Project SAFE. Poster presented at the Association for Behavioral and Cognitive Therapies Convention, Washington, DC.

Smith, H. D., Fromuth, M. E., \& Morris, C. C. (1997). Effects of gender on perceptions of child sexual abuse. Journal of Child Sexual Abuse, 6, 51--63.

Spaccarelli, S., \& Kim, S. (1995). Resilience criteria and factors associated with resilience in sexually abused girls. Child Abuse \& Neglect, 19, 1171-1182.

Steel, J., Sanna, L., Hammond, B., Whipple, J., \& Cross, H. (2004). Psychological sequelae of childhood sexual abuse: Abuse-related characteristics, coping strategies, and attributional style. Child Abuse \& Neglect, 28, 785-801.

Swenson, C. C., \& Chaffin, M. (2006). Beyond psychotherapy: Treating abused children by changing their social ecology. Aggression and Violent Behavior, 11, 120-137.

Touliatos, J., \& Lindholm, B. W. (1974). Influence of parental expectancies and responsiveness on achievement motivation of minimally brain-injured and normal children. Psychological Reports, 35, 395-400.

\section{Authors}

Haig Kouyoumdjian, $\mathrm{PhD}$, received his doctorate degree from the University of NebraskaLincoln and is currently an Assistant Professor in the Social Sciences Division at Mott Community College in Flint, Michigan.

Andrea R. Perry, MA, received her doctorate degree from the University of Nebraska-Lincoln and is currently a postdoctoral fellow in the Trauma Recovery Program at VA Palo Alto Health Care System.

David J. Hansen, PhD, received his doctorate degree from the University of Mississippi and is currently Professor and Chair of the Department of Psychology at the University of Nebraska-Lincoln. 